\title{
CHEGOU A HORA? O PROCESSO DE SUCESSÃO DE UMA PEQUENA EMPRESA FAMILIAR
}

\author{
THE TIME ARRIVED? THE SUCCESSION PROCESS OF A SMALL FAMILY BUSINESS
}

\author{
PATRINÊS APARECIDA FRANÇA ZONATTO ${ }^{1}$ \\ AMANDA PATERNO SBISSA ${ }^{2}$ \\ SAYONARA DE FÁTIMA TESTON ${ }^{3}$ \\ VINÍCIUS COSTA DA SILVA ZONATTO ${ }^{4}$
}

\begin{abstract}
RESUMO: Este caso para ensino tem como objetivo analisar o processo de sucessão em uma pequena empresa familiar, a Werner Cia Ltda. Passados 40 anos desde que fundou sua empresa, o Senhor Adroaldo se vê cansado, com a saúde debilitada, e priorizando aproveitar o tempo de vida que ainda lhe resta, acredita que está na hora de passar a empresa para que os filhos administrem e continuem com o negócio. Ocorre, que o fundador se pergunta a todo momento: será que meus filhos estão prontos e aptos para administrarem a empresa? O Caso apresenta estratégias analisadas no processo sucessório adotadas por uma pequena empresa do ramo de vidraçaria. O caso para ensino pode ser utilizado como material didático em cursos de graduação e de pós-graduação em administração e áreas afins. A elaboração do texto seguiu uma metodologia apropriada para caso para ensino. Os aspectos apresentados têm por objetivo possibilitar a discussão de conceitos de Pequenas Empresas Familiares, o Processo Sucessório, Competências Empreendedoras e sua associação com a prática empresarial vivenciada pelas empresas. Após a análise da situação apresentada, os alunos são convidados a discutir sobre o perfil do empreendedor, propondo estratégias, sob a ótica da teoria tridimensional, para que o processo sucessório ocorra de maneira satisfatória e não prejudique o crescimento e desenvolvimento da empresa. 0 caso é finalizado com notas de ensino e sugestões de aplicação em sala de aula.
\end{abstract}

PALAVRAS-CHAVE: Processo Sucessório; Competências Empreendedoras; Empresas Familiares.

ABSTRACT: This case for teaching aims to analyze the succession process in a small family business, the Werner Cia Ltda. Mr. Adroaldo has spent 40 years since he founded his company. He is tired, with poor health, and prioritizing to take advantage of the remaining life, believes that it is time to move the company so that the children manage and continue with the business. It so happens that the founder always asks himself: Will my children be ready and able to run the company? The Case presents strategies analyzed in the succession process adopted by a small company in the glassmaking business. The case for teaching can be used as didactic material in undergraduate and postgraduate courses in administration and related areas. The drafting of the text followed an appropriate methodology for cases for teaching. The aspects presented are intended to enable the discussion of concepts of

Data de submissão: 31/07/2017 Data de aceite: 14/05/2018 Data de publicação: 02/06/2018

1 Doutora em Administração pelo Programa de Pós-graduação em Administração da Universidade do Vale do Itajaí UNIVALI (2015-2018) / Bolsista CAPES

2 Doutoranda em Administração pela Universidade do Vale do Itajaí - UNIVALI (2018-Atual)

3 Doutoranda em Administração pela Universidade do Vale do Itajaí - UNIVALI

4 Pós Doutor em Ciências Contábeis pela Universidade do Vale do Rio dos Sinos - UNISINOS (2016). Atualmente é Professor

Permanente da FURB 
Small Family Businesses, the Succession Process, Entrepreneurial Skills and their association with business practice experienced by companies. After analyzing the presented situation, the students are invited to discuss the profile of the entrepreneur, proposing strategies, from the perspective of three-dimensional theory, so that the succession process occurs in a satisfactory way and does not jeopardize the growth and development of the company. The case is finished with teaching notes and suggestions for classroom application.

KEYWORDS: Succession Process; Entrepreneurial Skills; Family Business.

\section{CONTEXTO DO CASO}

Em 1970, os recém-casados Sr. Adroaldo e dona Cidônia chegam a cidade de Chapecó, localizada no oeste do estado de Santa Catarina, para iniciarem uma nova vida, deixando para trás a lida do campo no interior do Rio Grande do Sul, e vindo em busca de novos desafios na cidade cheia de novidades.

O senhor Adroaldo logo se preocupou em conseguir um trabalho para sustentar sua família e não demorou muito teve a sorte de conseguir trabalho em uma pequena empresa, a Cardoso \& Filhos Ltda., que fabricava box para banheiros, à época somente acrílico; não existia box de vidro. Além dos boxes para banheiro também trabalhavam na fabricação da estrutura de alumínio onde encaixava o box.

No entanto, a alegria do Sr. Adroaldo durou pouco; meses após iniciar seu trabalho tão esperado e recompensador a empresa decidiu encerrar suas atividades, pois as vendas estavam fracas e o dono da empresa já estava com idade avançada e não queria mais continuar com as atividades. Da mesma forma, seus filhos não queriam tocar o negócio, pois um era formado em psicologia e o outro formou-se em medicina veterinária, nenhum com o dom para gestão, e também não residiam mais na cidade de Chapecó.

Foi nesse momento, então, que o Sr. Adroaldo fez uma proposta inusitada para o proprietário da empresa, apresentando-se interessado em estabelecer uma sociedade. Senhor Cardoso, o dono, aceitou, e Adroaldo ficou responsável em continuar as atividades juntamente com mais dois funcionários que a empresa já possuía. Sr. Cardoso, após aceitar o desafio, passou toda a responsabilidade para o Sr. Adroaldo, que tinha um rápido raciocínio e já tinha aprendido toda a parte de produção e instalação. Além disso, sabia tratar seus clientes de maneira muito cordial. Adroaldo, apesar de morar boa parte de sua vida no interior, era esperto e sabia lidar com as atividades na agricultura: vendia seus produtos em feiras, comercializava produtos derivados do leite na cidade, como queijo, nata, bolos etc.. Já possuía, portanto, um dom para o comércio e sabia como manter um atendimento cordial e hospitaleiro.

Passados cinco anos, em 1976, a empresa ia muito bem, com excelente retorno financeiro; foi então que Senhor Adroaldo deu um passo ainda maior, juntou suas economias e fez uma proposta de compra da empresa ao Senhor Cardoso. O negócio foi efetivado, e então surgiu a Werner e Cia Ltda., que está até os dias atuais em pleno funcionamento.

\section{O CRESCIMENTO DA EMPRESA WERNER}


A empresa Werner iniciou sua trajetória de sucesso em 1976, somente trabalhando com a instalação de box para banheiro de acrílico; por volta de 1982 a empresa ampliou seu ramo, hoje fabrica os seguintes produtos: box para banheiro de acrílico e vidro temperado; portas, janelas, fachadas em vidros temperados e alumínios; portões, cercas, proteções para sacadas, coberturas fixas em policarbonato, balcões, telas mosqueteiras tudo em alumínio; e, cortes de vidros comuns para portas e janelas, e espelhos. A empresa dispõe de alumínio nas cores anodização: bronze e prata (fosco); pintura eletrostática: branco, preto e bege, e os vidros são temperados 8 a $10 \mathrm{~mm}$ nas cores: incolor, fume, verde, bronze e fosco (pontilhado e antílope).

A empresa conta com uma equipe de dezessete funcionários. A estrutura administrativa é formada por três colaboradores, sendo um responsável pela parte administrativa e de gestão de pessoas, outro responsável pela parte financeira e o terceiro colaborador atua na parte de relacionamento com os clientes e em serviços administrativos operacionais de escritório. Outros dois funcionários fazem parte da equipe de montagem, fazendo as instalações dos produtos a domicilio. O demais integrantes do quadro funcional são lotados na produção.

Nesta equipe de dezessete funcionários estão também os dois únicos filhos do Sr. Adroaldo e da dona Cidônia, Fernando e Fábio. Os dois são casados e suas esposas também trabalham na empresa, na parte administrativa. Quando os dois nasceram, o Sr. Adroaldo já possuía a empresa, mas estava apenas iniciando. Com o passar dos anos a empresa vem desenvolvendo e inovando para poder se manter no mercado. O Fernando e o Fábio não chegaram a cursar nenhum curso superior, fizeram apenas o ensino médio e, desde pequenos, já se envolveram nas atividades da empresa junto com seus pais.

Os filhos não possuem cargos específicos na empresa, ajudam em todos os setores, onde houver maior necessidade. Fernando, o filho mais velho, é casado com Fabiane, é mais tímido, com um comportamento mais introvertido, tem mais dificuldade na comunicação entre os setores da empresa. Com maior atuação no chão da fábrica, possui vasta experiência na área da produção e instalação dos produtos fabricados. Como o Sr. Adroaldo frisou "esse menino sempre teve muita facilidade para aprender o que eu ensinava pra ele na produção, falava uma vez e ele já saia fazendo, isso desde criança, puxou a mim."

Já o Fábio, casado com a Júlia, sempre atuou mais na área comercial, é mais falante, sabe negociar muito bem, tem alto poder de barganha junto aos fornecedores. Presta um bom atendimento aos clientes, tanto na empresa como na visitação a domicílio para fornecer orçamento. Fábio sempre se envolveu mais na parte burocrática da empresa, gostava mais de acompanhar o seu funcionamento. Sr. Adroaldo relata: "o Fábio nunca gostou de se sujar na produção (risos), sempre quis ficar sentadinho no ar condicionado, mas sabe negociar muito bem, quando chega os fornecedores, deixo pra ele conseguir preços melhores." Embora o Fernando consiga cuidar da produção, o processo é acompanhado diariamente pelo Sr. Adroaldo. Apesar de Fábio levar jeito para as compras e saber negociar muito bem, elas só se efetivam depois da autorização do Sr. Adroaldo, que analisa se a empresa dispõe de capital para a compra e pede aos fornecedores prioridade nos prazos de entrega da matéria prima.

Embora os filhos trabalhem na empresa a bastante tempo, possuindo certa experiência, eles nunca tiveram a permissão do Sr. Adroaldo para gerenciarem sozinhos as 
atividades relacionadas ao negócio; isso nunca ocorreu por que os irmãos divergem frente a algumas situações. O Fernando, por exemplo, não concorda com os horários do funcionamento da empresa, entende que não há necessidade de fazer só 1 hora de descanso para o almoço, acha que precisa um tempo maior e também entende que a empresa não deveria abrir aos sábados. Em sua opinião teria que ser dia de descanso dos funcionários, opinião contrária a do Fábio, que entende que o sábado é um dos dias com maior movimento na empresa.

Por outro lado, Fábio entende que os valores cobrados pelos produtos estão inferiores aos cobrados pelos concorrentes. Fernando acha que tem que manter esses valores, uma vez que o bom preço é o diferencial que faz a empresa se manter por tanto tempo no mercado. Fábio também acha que a empresa tem que investir mais em publicidade e propaganda, opinião contrária a de Fernando, que entende que o investimento em marketing pode gerar alto investimento para empresa, além de impactar em seus salários.

A questão relacionada aos lucros da empresa, ou especificamente à definição de seus salários, é algo que preocupa bastante Fernando e Fábio. Os mesmos estão registrados conforme a Consolidação da Leis de Trabalho (CLT), igualmente aos demais funcionários, com a diferença de que eles ganham participação nos resultados da empresa mensalmente, ou seja, quanto mais a empresa lucrar naquele período, maior será o retorno. A empresa não trabalha com nenhum tipo de marketing, a credibilidade e a boa reputação de quarenta anos no mercado é o que garante à empresa se manter em pleno funcionamento, conforme destaca o fundador Sr. Adroaldo. Este, não possui curso superior, conta apenas com sua expertise na prospecção de novos clientes. A marca reconhecida, preço, prazo de entrega e o bom atendimento são alguns dos fatores que se destacam na empresa, para que a mesma possa estar atuando e crescendo, mesmo depois de surgir tantos concorrentes no mesmo mercado de atuação.

O Sr. Adroaldo é quem abre a empresa todos os dias, é o único gestor e administrador da empresa, tudo tem que passar por ele, que aprova ou rejeita uma decisão. A Fabiane, esposa do Fernando, filho mais velho, é o braço direito do Sr. Adroaldo, pois possui um bom conhecimento das atividades rotineiras da empresa devido ao tempo que está lá. Fabiane tem uma visão maior do negócio, possui curso técnico em contabilidade, auxiliando o Sr. Adroaldo na parte das finanças, inclusive, implantou um sistema informatizado de entradas e saídas na empresa. Até então, o registro de pagamentos e compras era feito de forma manual pelo Sr. Adroaldo em seus cadernos.

A Dona Cidônia não trabalha mais na empresa, ajudava anteriormente operando o caixa, na organização do escritório, no preparo do café, atividades essas que repassou a sua nora Júlia, esposa de Fábio.

\section{ANÁLISE E DILEMA DO CASO}

Após quarenta anos de empresa, Sr. Adroaldo se vê cansado e decide que está na hora de descansar, cuidar de sua saúde e aproveitar um pouco a vida, mas, para que isso aconteça, é preciso passar o comando da empresa para seus filhos. Então, Adroaldo se vê frente ao um grande dilema: "será que meus filhos estão prontos e aptos para administrarem a empresa?". Esta indagação se deve ao fato que os dois filhos divergem em 
muitas situações, o que leva o Sr. Adroaldo a perder o sono, com receio que a empresa encerre suas atividades, uma vez que não vê os filhos com competências para manter e dar continuidade ao negócio.

Os irmãos Fernando e Fábio sempre trabalharam na empresa dos pais. Desde crianças acompanhavam diariamente o pai e a mãe no trabalho. Mas sempre trabalharam e ajudaram porque a empresa pertencia a família, nunca tiveram muita vocação para gerenciar o negócio, e também nunca executaram outra atividade diferente em outro lugar, a não ser no negócio da família.

Os irmãos também não se veem trabalhando na empresa a longo prazo. Eles permanecem na empresa porque ela é familiar, mas não se veem com características empreendedoras, inovadoras, não são criativos, ou seja, não têm nenhuma ideia do que é necessário e fundamental para que a empresa possa continuar em funcionamento e, principalmente, dando retorno financeiro. Simplesmente executam atividades rotineiras que estão acostumados a fazer, uma vez que é a fonte de renda de ambos. Não possuem uma visão de longo prazo para a empresa, nem ao menos traçam metas futuras para o prosseguimento da mesma.

Um dos fatores que mais preocupa o Sr. Adroaldo em passar o comando da empresa aos filhos é que sempre existiu muitos conflitos entre os dois irmãos diante de questões relacionadas ao trabalho. Os dois irmãos querem ter o mesmo poder de liderança, divergem sobre os valores cobrados nos produtos e serviços prestados, sobre horários de funcionamento da empresa e, além disso, querem receber uma participação maior nos resultados.

Isso foi um dos motivos que fez com que o Sr. Adroaldo continuasse por mais tempo no comando da empresa, pois não vê seus filhos capazes de dar continuidade nos negócios da família; são individualistas, pensam apenas em seus ganhos individuais. Sr. Adroaldo e dona Cidônia temem, frente a tudo isso, que a empresa possa acabar se desfazendo, em virtude dos conflitos internos dos filhos e sua incapacidade de gestão. Uma eventual situação como essa pode vir a prejudicar a toda a família, porque além dos filhos, suas esposas também trabalham na empresa há anos. Fora isso, pensam em todos os funcionários que dependem exclusivamente da Werner para o sustento de suas famílias.

Entretanto, tendo em vista a idade avançada do Sr. Adroaldo e a sua saúde debilitada em virtude de problemas cardíacos, é preciso tomar a decisão sobre seu afastamento, pois vai chegar o momento de se deixar a gestão da empresa e, de maneira natural, promover o processo de sucessão na Werner Cia Ltda.

\section{NOTAS DE ENSINO}

\section{Obtenção dos Dados}

As informações descritas no texto foram todas coletadas a partir de entrevistas junto ao proprietário da empresa. Trata-se de um caso baseado em uma história real, porém os nomes da empresa e dos personagens citados no decorrer do texto foram alterados para preservar a identidade do caso analisado.

\section{Utilização Recomendada}


O caso foi elaborado para aplicação principalmente com alunos de graduação ou pósgraduação dos cursos de Administração, ou áreas afins, preferencialmente nas disciplinas de empreendedorismo, gestão empresarial, administração estratégica, teoria das organizações, psicologia organizacional e do trabalho, entre outras que contemplem a temática objetivo de análise do caso. Espera-se que o aluno, por meio do estudo do caso, desenvolva um entendimento sobre perfil empreendedor e as capacidades de gestão de empresas familiares e, principalmente, acerca do processo sucessório no contexto de pequenas e médias empresas, sobre aplicação dos conceitos teóricos na prática administrativa.

\section{Objetivos de Aprendizagem}

O caso de ensino apresenta uma situação em que o fundador e proprietário de uma pequena empresa especializada em box para banheiros, precisa decidir se chegou a hora de passar o comando de sua empresa para os filhos. Porém, o que tem lhe deixado mais inquieto e apreensivo é a dúvida se os filhos estão aptos para administrarem a empresa. Desta forma, pode-se destacar alguns temas de aprendizagem:

1. Verificar quais as possibilidades de mudança e analisar possíveis soluções para o dilema.

2. Identificar fatores de atitude empreendedora nos filhos do proprietário da empresa.

3. Proporcionar discussões sobre os conceitos de empresas familiares, processo sucessório, e competências empreendedoras.

4. Promover reflexões sobre situações que permitam aos alunos analisar conceitos necessários para o processo de sucessão em empresas familiares.

5. Debater sobre a realidade enfrentada por pequenas empresas familiares frente às dificuldades financeiras e administrativas no decorrer de um processo de sucessão.

\section{SUGESTÃO DE PLANO DE ENSINO}

Como sugestão para a compreensão e análise do caso pelo professor, para que se possa orientar a discussão em sala de aula, sugere-se os seguintes passos:

a) preparação individual com leitura prévia dos alunos;

b) recomenda-se que o professor disponibilize um período para que os alunos discutam o caso em pequenos grupos;

c) discussão orientada pelo professor com apresentação de cada grupo; 
d) fechamento da discussão do caso pelo docente.

\section{QUESTÕES PARA DEBATER COM OS ALUNOS}

A seguir, apresenta-se um conjunto de questões que podem ser usadas para estimular a análise do caso durante a etapa de discussão:

1. A partir da análise do caso, que fatores o Sr. Adroaldo, enquanto gestor, deveria ter alinhado previamente para que o processo sucessório ocorresse de forma tranquila?

2. Quais resistências e obstáculos que os novos gestores possivelmente terão que enfrentar, após o processo sucessório, para que a empresa continue em desenvolvimento?

3. Analisando as atitudes e competências empreendedoras do Sr. Adroaldo quanto a criação e ao crescimento da empresa, quais seriam as suas sugestões de escolha estratégica com relação ao futuro da Werner e Cia Ltda?

4. Se você estivesse no lugar do Sr. Adroaldo, assumiria o risco de passar o comando da empresa para os filhos?

5. Em sua opinião, em que momento você acha que o Sr. Adroaldo percebeu que estava na hora tomar uma decisão em relação ao futuro da empresa?

\section{ABORDAGENS TEÓRICAS RECOMENDADAS}

Para auxiliar o professor quando da aplicação deste caso, os autores sugerem algumas teorias de suporte que poderão ser utilizadas durante o processo de discussão e aprendizagem. Neste item serão abordadas teorias relacionadas a empresas familiares, processo sucessório e competências empreendedoras.

\section{EMPRESAS FAMILIARES E SUCESSÃO SOB A ÓTICA DO MODELO TRIDIMENSIONAL}

Para a análise deste Caso, sugere-se a análise do modelo tridimensional, também conhecido como modelo três Círculos de Gersick et al. (1997). Este modelo considera a teorização e explicação do axioma fundamental das empresas familiares: a sucessão (LAMBRETCH, 2005). Gersick et al. (1997) descrevem a empresa familiar como um fenômeno constituído por três subsistemas: gestão, propriedade e família. O modelo é ilustrado na Figura 01.

Figura 01 - Modelo dos três círculos 




Fonte: Elaborado com base em Gersick et al. (1997, p. 06)

Segundo este modelo, qualquer indivíduo inserido em uma organização familiar pode ser enquadrado em pelo menos um dos sete setores ou eixos que se originam da interação dos três subsistemas (GERSICK et al., 1997). Sob esta ótica, busca-se analisar, interpretar e propor sugestões de nas empresas familiares. Cada uma das áreas distintas representa diferentes agentes envolvidos na empresa familiar.

Para Casillas et al. (2007) no eixo 1 encontram-se todos os familiares, que não possuem ações ou cotas e não exercem funções diretivas na empresa; ao eixo 2 pertencem aqueles que possuem ações ou cotas da empresa familiar, mas não exercem função diretiva e não pertencem à família; já no eixo 3 estão os profissionais que não são membros da família e fazem parte da gestão. Por sua vez, no eixo 4, encontram-se os indivíduos que são proprietários, mas não ocupam cargos executivo na empresa; no eixo 5, reúnem-se os indivíduos que não são membros da família, mas participam da propriedade e desenvolvem funções de direção. Já no eixo 6 , estão os membros da família que desenvolvem funções executivas ou de direção, porém não possuem ações ou cotas e, finalmente, no eixo 7 , encontram-se todos os membros que possuem ações ou parte da propriedade da empresa e ocupam cargos de direção (CASILLAS et al., 2007).

Os três fatores e seus respectivos eixos e o ciclo de vida da organização parecem demonstrar conexão no modelo de Gersick et al. (2007). Nas empresas familiares este tipo de análise prioriza a relação de transformação da empresa e de suas estruturas com a passagem do tempo e a presença de eventos marcantes e este aspecto dá sustentação ao fato de que a sucessão é um processo e não um evento em uma empresa (TESTON, 2014). Parte-se assim da premissa que a evolução simultânea dos três subsistemas do modelo e o foco de todos os integrantes da empresa em um mesmo objetivo de médio e longo prazos atribuem maior possibilidade de sustentabilidade (GERSICK et al., 2007). Uma ilustração sobre o ciclo de vida das organizações pode ser analisada na Figura 02.

Figura 02 - Modelo Tridimensional de Evolução da Empresa Familiar 


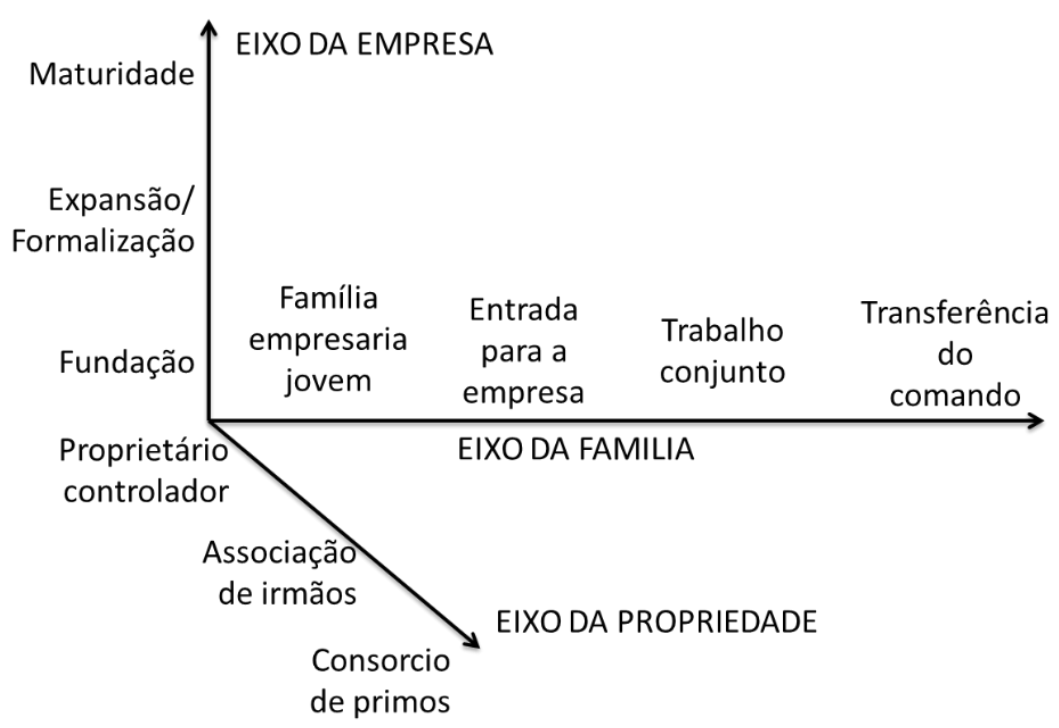

Fonte: elaborado com base em Gersick et al. (1997).

Sabe-se que para cada etapa da evolução do ciclo de vida, diferentes desafios surgem e que envolvem todos os eixos do modelo tridimensional.

Para Casillas et al. (2007), no eixo da empresa, há a etapa da fundação, na qual ocorre principalmente a preocupação pela sobrevivência e formalização do projeto do fundador, neste momento há preocupação voltada para a pressão gerada pela necessidade de manutenção e desenvolvimento da empresa no mercado. Na etapa de expansão/ formalização, busca-se o estabelecimento de estruturas de gestão, sistemas e procedimentos formalizados. Já na etapa de maturidade, almeja-se a revitalização por meio de processos ou renovações estratégicas (CASILLAS et al. 2007). Muitas vezes, o processo de sucessão se consolida na maturidade, e o gestor precisa escolher se a sucessão ocorrerá por meio do processo de desenvolvimento de competências empreendedoras nos filhos, ou se será feita a sucessão por meio de profissionais não familiares.

Para Gersick et al. (2007) no eixo da família o primeiro momento é a etapa da família jovem, quando ocorrem decisões acerca da formação profissional dos cônjuges e quais princípios orientarão a vida dos filhos. Na etapa de entrada para os negócios, ocorre o processo de escolha profissional para os filhos, neste Caso, os filhos optaram por profissões da área da saúde, apesar de as competências empreendedoras serem aspectos que podem ser desenvolvidos (CHELL, 2008). Além disso, a fase de entrada para os negócios e escolha profissional também pode ser marcada por conflitos geracionais (GERSICK et al., 2007). Na etapa da família que trabalha em conjunto a clareza na diferenciação dos papéis de cada membro familiar no trabalho, as habilidades interpessoais de ambas as gerações para trabalharem juntas, e o processo de reconhecimento dos sucessores parecem ser de fundamental importância para o processo (TESTON, 2014). Na última etapa, constituída pela transferência do comando da empresa, cede-se o comando para a próxima geração e efetiva-se o processo de sucessão (CASILLAS et al., 2007).

No eixo da propriedade, existe a fase em que o proprietário centraliza e controla a totalidade dos negócios, enquanto na etapa de associação de irmãos, a empresa geralmente possui membros da segunda geração como funcionários e, na etapa de consórcio de primos, a terceira geração já ingressou nos negócios (CASILLAS et al., 2007). Com foco no processo 
de sucessão, quando há transferência da primeira para a segunda geração, parecem ser necessárias habilidades para lidar com pressões de diferentes ramos da família, bem como, com conflitos interpessoais.

De acordo com Gersick et al. (1997), a primeira lição é tratar a empresa como empresa, a família como família e a propriedade com respeito, a segunda lição é ter sempre em mente a natureza constante e inevitável das mudanças ligadas ao desenvolvimento. A mudança surge como inevitável e inerente ao ciclo de vida da empresa e o modelo dos três círculos pode ser útil para entender a história e a evolução dela, focalizando principalmente as mudanças ocorridas no decorrer do tempo, o que contribui para que os sucessores em processo de preparação consigam trabalhar com os desafios de cada etapa de forma preventiva.

Gersick et al. (1997, p. 108), "vê as organizações mudando em uma sequência previsível de estágios, motivados em parte por condições no ambiente externo, mas principalmente, por complexos fatores maturativos internos à organização". Certamente, o conhecimento acerca dos estágios e dos possíveis desafios intrínsecos a cada um deles pode contribuir para o planejamento de um processo de sucessão, que conte com profissionais familiares ou não familiares para compor a gestão e garantir longa vida à empresa, haja vista que a "sucessão é um dos maiores desafios para as empresas familiares" (TESTON; FILIPPIM, 2016, p. 525).

\section{COMPETÊNCIAS EMPREENDEDORAS}

Schumpeter (1982) traça um perfil do empreendedor descrevendo-o como aquele que persegue a realização do seu sonho, sendo um indivíduo que busca conquistar seus ideais, com motivação para lutar pelo sucesso e para quem o retorno financeiro pecuniário é a expressão consumada do sucesso. Esse tipo perfil de personalidade, segundo o autor, seria "inato" ao indivíduo empreendedor.

No mesmo sentido, o autor Filion (1999) descreve algumas características dos empreendedores, como: 1) são comprometidos com a realização de sonhos; 2) investem tempo planejando como e onde querem chegar; 3) se preparam para o inusitado, inclusive treinando seus colaboradores.

A ligação das competências com as ações dos empreendedores deu origem a criação da definição de competências empreendedoras, conceituadas por Snell e Lau (1994) como características pessoais, valores, atitudes ou visões, motivações ou direcionamentos que, contribuem para o pensamento ou ação efetiva do negócio. As competências empreendedoras, conforme os autores, estão relacionadas ao plano de vida do empreendedor.

No mesmo sentido, Antonello (2005) argumenta que conceito de competência empreendedora está próximo dos conceitos de competências individuais, e define como um conjunto de conhecimentos, habilidades e atitudes que impulsionam o indivíduo a expressar seus valores e sua visão por meio de estratégias e ações para a criação de valor tangíveis e intangíveis para a sociedade.

Alguns autores têm se preocupado em criar tipologias que possibilitem a identificação, de conhecimentos, habilidades, atitudes relativas às competências empreendedoras. O trabalho de Cooley (1990) estabelece dez competências 
empreendedoras: 1) busca de oportunidade e iniciativa; 2) persistência; 3) comprometimento; 4) exigência de qualidade e eficiência; 5) assunção de riscos calculados; 6) estabelecimento de metas; 7) busca de informações; 8 ) planejamento e monitoramento sistemáticos; 9) persuasão e rede de contatos; 10) independência e autoconfiança.

No mesmo sentido de categorizar as competências empreendedoras, os autores Man e Lau (2000) realizaram estudos empíricos entre 1993 a 1999 que resultaram em uma categorização de competências em seis áreas distintas apresentadas no Quadro 01.

Quadro 01 - Tipologia de Competências Empreendedoras

\begin{tabular}{|l|l|l|}
\hline \multicolumn{1}{|c|}{ Tipos de competências } & \multicolumn{1}{|c|}{ Conceito } & \multicolumn{1}{c|}{ Autor } \\
\hline Competências de Oportunidade & $\begin{array}{l}\text { Relacionada a identificação, avaliação e } \\
\text { busca de oportunidades. }\end{array}$ & Filion, 1999 \\
\hline Competências de Relacionamento & $\begin{array}{l}\text { Abrangem os contatos familiares e as } \\
\text { pessoas mais próximas; Assim como } \\
\text { amizades e grupos sociais: clubes, religião, } \\
\text { política, trabalho e contatos com que } \\
\text { ocorrem através de viagens, cursos e feiras. }\end{array}$ & Filion, 1999 \\
\hline Competências de Conceituais & $\begin{array}{l}\text { Capacidades de avaliar situações de risco, } \\
\text { além de capacidade de perceber situações } \\
\text { por ângulos diferentes e de forma positiva. }\end{array}$ & Dornelas, 2007 \\
\hline Competências Administrativas & $\begin{array}{l}\text { Capacidade de planejar, organizar, } \\
\text { comandar, motivar, delegar e controlar. }\end{array}$ & Man e Lau, 2000 \\
\hline Competências Estratégica & $\begin{array}{l}\text { Capacidade de implementação das } \\
\text { estratégias, o empreendedor visualiza } \\
\text { panoramas de longo prazo e objetivos de } \\
\text { médio e curto prazo alcançáveis e realistas. }\end{array}$ & Man e Lau, 2000 \\
\hline Competência de Comprometimento & $\begin{array}{l}\text { Dedicação do empreendedor e do seu } \\
\text { trabalho árduo, participando de tudo o que } \\
\text { acontece na organização. }\end{array}$ & Man e Lau, 2000 \\
\hline
\end{tabular}

Fonte: Elaborado com base em Man e Lau (2000).

A primeira competência de oportunidade apresentadas no Quadro 01, descritas pelos autores Man e Lau (2000), se refere a busca de identificar, avaliar e buscar uma nova oportunidade, um novo começo. Já a competência de relacionamento está associada aos contatos familiares e as pessoas mais próximas; bem como amizades e grupos sociais: clubes, religião, política, trabalho e contatos com que ocorrem através de viagens, cursos e feiras.

Por sua vez, a competência conceitual está ligada à capacidade e habilidade que o indivíduo possui de avaliar situações de risco, além de capacidade de perceber situações por ângulos diferentes e de forma positiva para lhe favorecer. A quarta competência é a administrativa, que é basicamente todo o processo de planejar, organizar, motivar, controlar etc. A competência estratégica se refere a capacidade de implementação das estratégias dentro da organização; o empreendedor tem uma visão de panoramas de longo prazo e objetivos de médio e curto prazo que são alcançáveis e realistas. E, por fim, a competência de comprometimento que está relacionada diretamente à dedicação do empreendedor e do 
seu trabalho árduo, participando da tomada de decisão de tudo o que acontece dentro da organização.

\section{DESFECHO DO CASO}

Após dois anos pensando e analisando, Sr. Adroaldo percebeu que havia chegado a hora de parar de trabalhar, descansar e cuidar de sua saúde e, então, passar a sucessão da empresa para os seus filhos. Neste momento, já certo de sua decisão, Sr. Adroaldo chegou a um entendimento que a melhor pessoa que pudesse administrar a empresa não seria nenhum dos seus dois filhos, o Fernando e o Fábio, mas a sua nora Fabiane.

A participação ativa de Fabiane, com muita competência, nas atividades da empresa ao lado do Sr. Adroaldo, em áreas administrativa e financeira, fez com que o fundador observasse a sua capacidade de gestão, ética, habilidade na execução das tarefas, comprometimento e dedicação ao negócio da família, por mais da metade de sua vida.

Fabiane é casada a quinze anos com o Fernando, filho mais velho do Sr. Adroaldo e da dona Cidônia, e começou a trabalhar na empresa desde que casou. É responsável por toda a parte administrativa, cuidando das áreas de compras, recursos humanos, contabilidade, etc.

Antes de se casar e começar a trabalhar na Werner, Fabiane fez um curso técnico em contabilidade e atuou por cinco anos em um escritório de contabilidade, trabalhando como assistente administrativa. Atualmente, está no terceiro ano do curso de graduação em administração e possui um vasto conhecimento nas atividades que já executava, nas áreas administrativa e contábil. Sempre se dedicou muito ao seu trabalho, desenvolvendo as atividades a ela atribuídas com muita dedicação e competência.

Hoje, passados quatro anos desde que recebeu o bastão do então sogro e fundador Sr. Adroaldo, Fabiane é gerente geral da Werner Cia Ltda. O faturamento da empresa teve um acréscimo de $20 \%$ em vendas. Essa mudança positiva o Sr. Adroaldo atribui ao sangue novo da empresa e a excelente gestão da Fabiane, que não mediu esforços para se dedicar ainda mais a empresa, mudando imediatamente toda a estrutura, adaptando e inovando, trazendo motivação e força de vontade para a equipe.

A empresa Werner passou por uma restruturação no comando da Fabiane, algumas coisas que podem ser citadas são: em relação à inovação, a criação de um site apresentando a empresa; propagandas semanais no jornal da cidade; mudou toda a estrutura física e a fachada da empresa, deixando com um ar mais moderno e inovativo; criação de uniforme para toda a equipe, e também buscou junto ao Sebrae cursos de capacitação e treinamento para todos os funcionários. A mudança mais significativa foi a ampliação da linha de produtos, a empresa começou a instalar vidros decorativos também, como: espelhos, aparadores e tampos de mesas e painéis de espelhos. A Werner monta, instala e faz a manutenção do seus produtos e serviços.

Percebe-se que o crescimento e o desenvolvimento da empresa familiar, mesmo após o processo de sucessão, também está relacionado com as competências empreendedoras da Fabiane, tais como determinação, persistência, habilidade e capacidade organizacionais, capacidade de gestão e capacidade inovativa, além de todo o comprometimento com interesses individuais e da organização, além da liderança criativa. 
Por sua vez, o Sr. Adroaldo e a dona Cidônia mudaram-se para uma praia pequena no norte do estado de Santa Catarina, buscando uma vida mais calma, e só visitam a empresa uma vez por mês. Estão muito felizes com os resultados que a empresa vem alcançando e não se arrependem da decisão. Os filhos continuam trabalhando na empresa sobre a gestão da Fabiane; seu marido Fernando continua executando suas funções na área da produção e ajudando no que mais for preciso na empresa. O outro filho, Fábio, também continua executando suas atividades na área comercial e sua esposa Júlia, que ficava no caixa, foi promovida ao cargo que a Fabiane ocupava antes da sucessão.

$\mathrm{Na}$ administração de Fabiane, as divergências entre os irmãos acabaram, ela não permite desentendimento entre quaisquer que sejam os funcionários, muito menos entre os irmãos e hoje o clima é de paz e harmonia. Todos retratam a Fabiane como gestora e a respeitam e, para conseguir manter essa cultura, Fabiane faz uma vez por mês um café na empresa com todos os funcionários, momento em que os colaboradores podem expressar seus descontentamentos, divergências e alinhar os pontos pendentes, para que possam continuar crescendo e se desenvolvendo.

\section{REFERÊNCIAS}

ANTONELLO, C. S. A metamorfose da aprendizagem organizacional: uma revisão crítica. Aprendizagem organizacional e competências. Porto Alegre: Bookman, p. 12-33, 2005.

CASILLAS, J. C.; VAZQUEZ, A.; DIAZ, C. Gestão da Empresa Familiar: Conceitos, casos e soluções. São Paulo: Thompson Learning, 2007.

CHELL, E. Social Enterprise and Entrepreneurship: Towards a Convergent Theory of the Entrepreneurial Process. International Small Business Journal, v. 25, n. 1, p. 5-26, 2008. COOLEY, L. Entrepreneurship Training and the Strengthening of Entrepreneurial Performance. Final Report. Washington: USAID, 1990.

DORNELAS, J. C. A. Empreendedorismo na prática: Mitos e verdades do empreendedor de sucesso. Rio de Janeiro: Elsevier, 2007.

FILION, L. J. Empreendedorismo: Empreendedores e proprietários-gerentes de pequenos negócios. Revista de Administração, São Paulo, v. 34, n. 2, p. 5-28, abr./jun. 1999.

GERSICK, K.; DAVIS, J. A.; HAMPTON, M. M.; LANSBERG, I. De geração para geração: ciclo de vida das empresas familiares. São Paulo: Negócio Editora, 1997.

LAMBRECHT, J. Multigenerational transition in family business: a new explanatory model. Family Business Review, v. 18, n. 4, p. 267-282, 2005. Disponível em: http://onlinelibrary.wiley.com/doi/10.1111/j.1741-6248.2005.00048.x/abstract. Acesso em: 19 julho 2017. 
MAN, T. W. Y.; LAU, T. Entrepreneurial competencies of SME owner/managers in the Hong Kong services sector: A qualitative analysis. Journal of Enterprising Culture,8, n. 3, p. 235254, Sept. 2000.

SNELL, R.; LAU, A. Exploring local competences salient for expanding small businesses. Journal of Management Development, v. 13, n. 4, p. 4-15, 1994.

SCHUMPETER, J. A. The Theory of Economic Development: An Inquiry into Profits, Capital, Credit, Interest, and the Business Cycle (1912/1934). Transaction Publishers.-1982.January, v. 1, p. 244, 1982.

TESTON, S. F. Como transformar rios em oceanos: uma proposta de preparação de sucessores para empresas familiares. 2014. 157 f. Dissertação (Mestrado Profissional em Administração), Universidade do Oeste de Santa Catarina, Chapecó, 2014.

TESTON, S. F.; FILIPPIM, E. S. Perspectivas e Desafios da Preparação de Sucessores para Empresas Familiares. Revista de Administração Contemporânea, Curitiba, v. 20, n. 5, p. 524545,2016 . Disponível em: http://www.scielo.br/scielo.php?script=sci_arttext\&pid=S1415$65552016000500524 \&$ Ing=en\&nrm=iso\&tlng=pt. Acesso em: 19 julho 2017. 